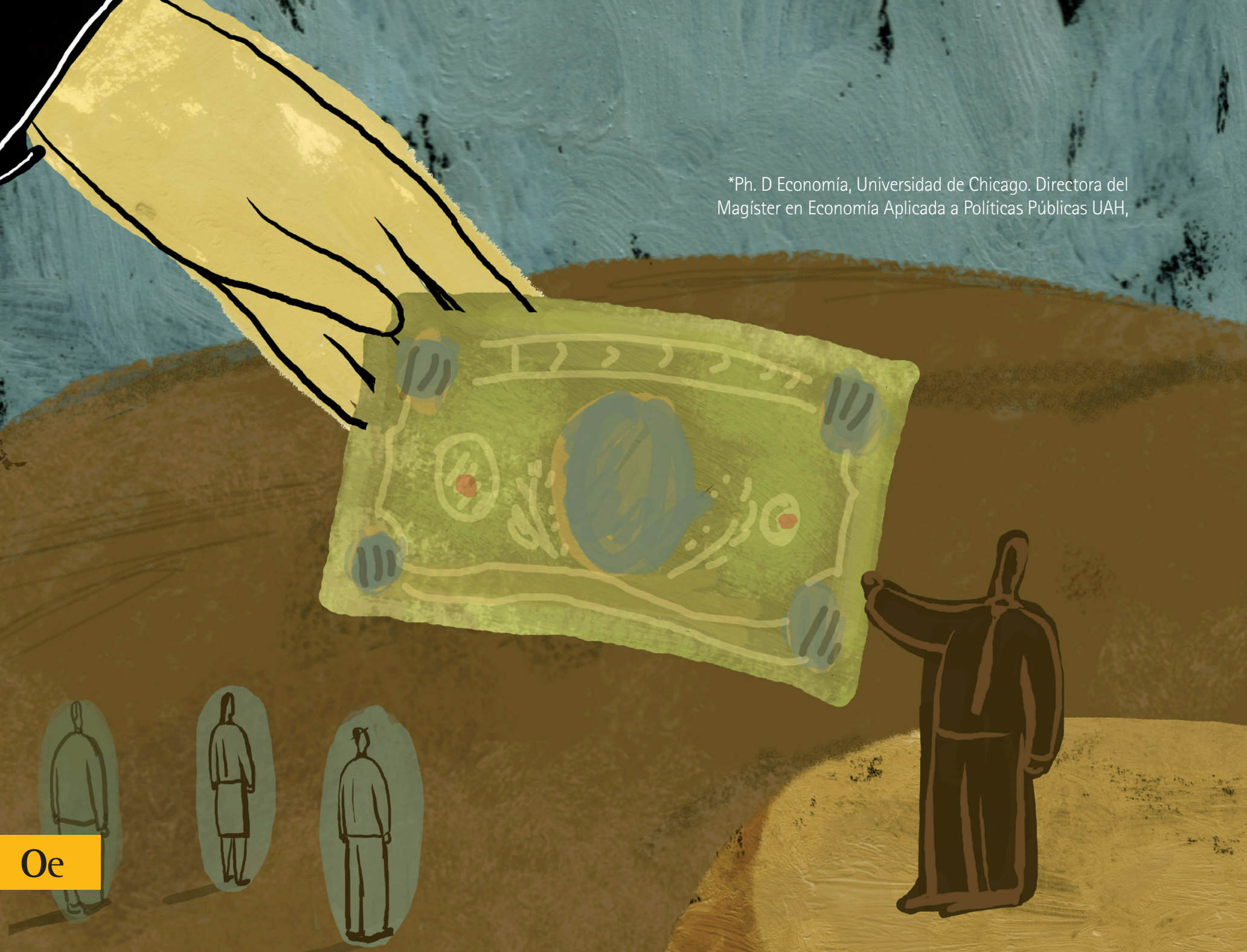

\title{
ORTODOXIA FISCAL VS ORTODOXIA MICRO
}

Por Andrea Butelman*

¿Qué es inversión? Si decide instalar en su casa un sistema de energía solar para generar electricidad -con lo que reducirá sus cuentas lo suficiente como para que en algunos años se pague la instalación, seguramente considerará que hizo una inversión. De hecho, la hizo. Para su riqueza -y por ende, para sus decisiones de consumo- tal inversión será equivalente a hacer un depósito a interés en el banco, si este último le diera igual rendimiento.

Suponga ahora que el Estado hace un desembolso en, por ejemplo, un sistema de energía para calefacción más limpia en ciudades que tengan altos indices de partículas en el aire debido a la calefacción a leña. Tal desembolso permitirá en años posteriores, reducir el gasto en salud, aumentar la productividad al evitar eventos de emergencia ambiental, mejorar rendimiento escolar, y varios beneficios más. 
Sin embargo, esta inversión tiene una menor probabilidad de realizarse que una inversión financiera, aun cuando esta última tenga menos rentablilidad.

Esa eficiente inversión que resuelve tantos problemas, en palabras de los expertos, "estará sobre la línea"- por lo que el Ministerio de Hacienda la mirará mal ya que contribuye al desbalance estructural. Probablemente eso la mate. Con tal camisa de fuerza, toda inversión o gasto -aunque sea rentable- deberá financiarse 0 , con una reducción de otros gastos o con nuevos impuestos. Reducir gastos no es tarea simple y hacer reformas tributarias tampoco, por lo que el "gasto" o inversión difícilmente se hará a través del erario público. Se debe enfatizar que es aún más difícil que la hagan los privados. En efecto, estamos frente a una externalidad y los beneficios de la inversión -por ejemplo, menor gasto en salud-, no tienen como ir a los bolsillos de un privado que invierta en ese tipo de calefacción más limpia.

La pregunta entonces es, por qué si un privado compara una inversión financiera y una inversión real sólo en base a su rentabilidad esperada, para el fisco es mucho más fácil inclinarse por una financiera. 0 en otras palabras, ¿por qué no se pueden realizar desembolsos claramente rentables?

La diferencia entre un consumidor e inversionista privado y el fisco, es que este último, dado su gran peso específico en la economía -y su rol estabilizador- debe preocuparse de cuál será el efecto en las variables macroeconómicas. Así, aunque una inversión o gasto genere suficientes ingresos - o reducciones en otros gastos-para pagar la deuda que genere, va a impactar de igual manera en el gasto global en el corto plazo, lo que puede generar inflación, aumentos del tipo de cambio y, en general, señales que distorsionan las decisiones de los agentes económicos privados. Es por eso que Chile ha adoptado una regla de balance estructural que limita la cantidad de gasto -ya sea inversión o consumo- que puede realizar el sector público.

"El Fondo Monetario Internacional ( $\mathrm{Da}$ bán, 2010) define a la regla de balance estructural como la "piedra angular del buen comportamiento fiscal de Chile". Entre las bondades ampliamente documentadas de la Politica de Balance Estructural chilena se puede mencionar que ha contribuido principalmente a reducir la volatilidad fiscal y macroeconómica, aumentar el ahorro público durante los ciclos económicos expansivos, reducir las percepciones de riesgo sobre la economía chilena, reducir la volatilidad de la tasa de interés y ayudar a sostener un tipo de cambio real más competitivo y menos volátil, lo que ha permitido resguardar la competitividad del sector exportador a pesar del pronunciado ciclo en el precio del cobre de los últimos años." (Larrain, et al , 2011)

Entonces, si no se pueden subir los impuestos ni reducir gastos ni tener déficit fiscal, puesto que ello distorsionaría las señales macroeconómicas que a su vez dañan la inversión, ¿cómo podemos financiar esos gastos tan necesarios? La gran tentación: establecer subsidios cruzados. Es decir, lograr que unos consumidores paguen, al menos parcialmente, la cuenta de otros. Esto es especialmente fácil de hacer para el Estado en los sectores cuyas tarifas son reguladas. Por ejemplo, durante muchos años la alta disparidad en los cargos de acceso, fijados por el Estado entre la telefonía móvil y la telefonía fija permitió que la primera creciera más respecto a la segunda y que Chile desplegara rápidamente su red de telefonía móvil. El resultado fue bueno, pero bastante más caro e ineficiente que si se hubiera hecho con sincera transparencia fiscal.

Así, los subsidios cruzados permiten llevar a cabo inversiones o gastos con "impuestos velados". Un ejemplo claro de esto es lo que propone la Comisión Asesora Presidencial para el Estudio y Propuesta de un Nuevo Modelo y Marco Jurídico para el Sistema Privado de Salud que recomendó que el 7\% de la -hasta ahora- cotización individual de salud pase a ser un aporte solidario. Este sería claramente un impuesto a los ingresos del trabajo, pero sería dinero que no iría a las arcas fiscales sino que a un fondo común para la salud.

Más allá de lo justa o injusta que se considere esta medida, especialmente, tomando en cuenta que no afecta a los ingresos provenientes del capital, debemos concordar en que tiene los mismos efectos que un impuesto y como tal, debiera evaluarse cuán distorsionador de la economía es versus otros impuestos. No cabe la menor duda que un impuesto al ingreso salarial, reduce los incentivos a trabajar, incita a la informalidad, y en definitiva tiene efectos perversos en la economía que no tienen por qué ser menores a las distorsiones en las señales macroeconómicas que genera un déficit fiscal, sobre todo si este está financiado por los ingresos futuros de la inversión pública.

Volviendo al caso de la calefacción en las zonas saturadas, una gran tentación es estructurar el mercado del gas natural de forma tal que sean los consumidores actuales los que financien la expansión de redes hacia las zonas a los que este aún no llega. Sin duda, es un impuesto velado, como todo subsidio cruzado. $Y$ muchos pueden pensar que hay una suerte de justicia social en ello. Sin embargo, más allá de las ineficiencias que surgen de las señales de precio que se entregaría a los consumidores finales del gas, debemos recordar que el gas también es utilizado con fines productivos y que nuestro país tiene graves problemas de competitividad por los altos precios de la energía. Así, cargarle a las empresas productivas el costo de reducir el uso de la leña en las ciudades del sur parece altamente ineficiente. Una política de este tipo no tiene por qué ser menos dañina para la inversión que un aumento en el "balance estructural".

¿Significa eso que debemos eliminar la regla de balance estructural? Por supuesto que no. Pero tampoco podemos suplir sus falencias distorsionando las señales microeconómicas que determinan la asignación de recursos.

Un pais que tiene problemas angustiantes-como la contaminación- cuya solución reduce con certeza gastos en el futuro inmediato-y, por tanto, no generará déficit alguno- no debe cerrarse a hacerlos,- en forma priorizada y gradual- aunque arriesgue en algún grado la estabilidad macroeconómica en el corto plazo "en vez de distorsionar la microeconomía para siempre.

Por último, es claro que es preferible hacer estos gastos en épocas de menor crecimiento, y diferenciar aquellos que tienen más impacto en el gasto interno de aquellos que tienen menos.

Larrain, F., R. Costa, R. Cerda, M. Villena, A. Tomaselli, "Una política fiscal de balance estructural de segunda generación para Chile" 